
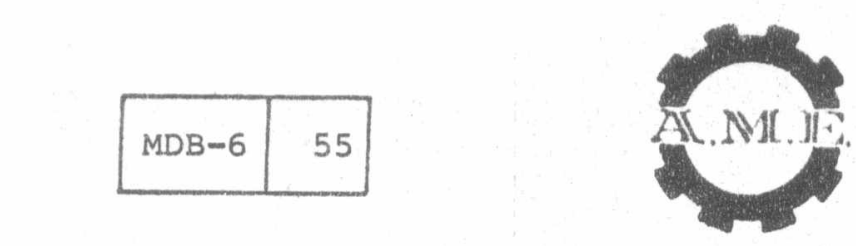

MILITARY TECHNICAL COLLEGE

CAIRO - EGYPT

\title{
FATIGUE CRACK GROWTH IN ALUMINUM ALLOYS
}

\section{UNDER PROGRAMMED BLOCK LOADING}

\author{
M.S. GABRA *
}

\section{ABSTRACT}

Using fracture mechanics principles, crack growth rates can be predicted accurately for some simple crack configurations: subjected to constant amplitude loading. However, for more complex loading sequences such as flight simulation loadings, the results are conservative by a factor 3 to 10 or more.

: The main objective of this study is to interpret the fatigue: behaviour of two aluminum alloys under programmed block loadings. The effects of cycle ratio $\mathrm{R}(\sigma \mathrm{min} / \sigma \mathrm{max})$ and material : thickness on crack propagation rate are analysed. Fatigue crack growth under programmed block loading is presented. Linear damage accumulation is established for some simple flight simulation tests. Aspects covered include microscopic. and fractographic observations. The incidence of crack closure is examined and the agreement between predictions and test results is very promising.

\section{INTRODUCTION}

In variable amplitude loading (V.A.L.) several effects are to. be considered to predict correctly the fatigue crack growth $/ \dot{y}$ Interaction effects are well manifested in the observed phenm omena defined as retardation or acceleration of cracking.This implies that the crack extention in a loading cycle $\Delta$ a will depend on what occured in the preceding cycles. $\Delta$ a will depend on such factors as crack tip blunting, shear lip development, crack closure, cyclic hardening and residual stresses. All these phenomena occur around crack tip $/ 2,3 /$. Schijve $/ 2 /$. has classified the various types of loading in five main groups, namely: overloads, step loading, programmed blocks, random loading and flight simulation loadings. Moreover, he/4/ simplified these groups in two main categories : stationary:

$\vdots$ V.A.I. where the sequence of load cycles is repeated excatly and regulary; non-stationary V.A.I. with no sequencial repeat-

* Col. Dr. Engineer, Dept. of Aeronautical Mech. Engineering, Military Technical College, Cairo, Egypt. 


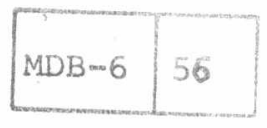

FIRST A.M.E. CONFERENCE

$29-31+4 y 1984$, Cairo

$r \cdots \cdots$

ion of a block of different load cycles. Elber / $5 /$ defined a short spectrum to be one where crack growth during one repeated interval is less than the plastic zone created by the highest load in the spectrum. Our study is undertaken to investigate the crack growth rate behaviour in 2124 I 351 and 2618 AT 651 aluminum alloys widely used in aeronautical structures. Programmed block loading was chosen to simulate some simple flight types of the standardized load sequence for flight simulation tests on transport aircraft wing structure (TWIST). TWIST program/6/ comprises ten different types of flight adopted to the mean stress in flight ( $1-g$ condition). The fact that the chosen block loadings have not introduced any interaction effects and consequently a Linear damage accumulation, implies that crack growth depends essentialiy on the stress intensity factor range $\mathrm{K}$ and cycle ratio $\mathrm{R}$. The good agreement between experimental cesults and prediction has directed our attention to determine the parameters of an equivalent constant amplitude sequence that replaces the original block loading in the crack grwoth calculations /7/. The developed concept is based on physical aspects of a amage and arack closure phenomena, approved by microscopic observations.

\section{TEST PROGRAM}

The test program was designed so that the crack growth under different cycle ratio $R$ would be investigated separately. The test matrix was defined in terms of three levels of loading: $A, B$ and $S$ with ratios $(R=0.01,0.63,0.45)$ respectively. The patterns and loading values for the programmed blocks. are shown in Fig. I. Type A is considered as a simple nondisturbed

$\mathrm{P}$

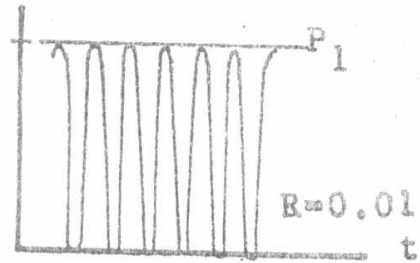

A

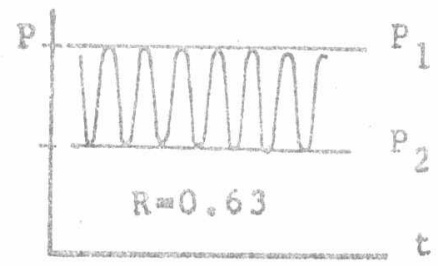

B

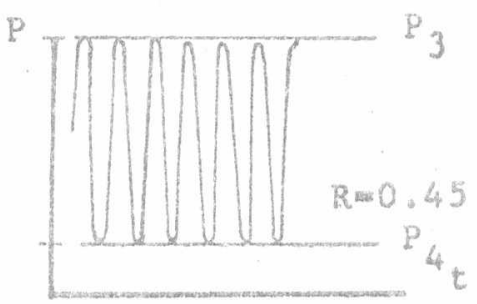

S

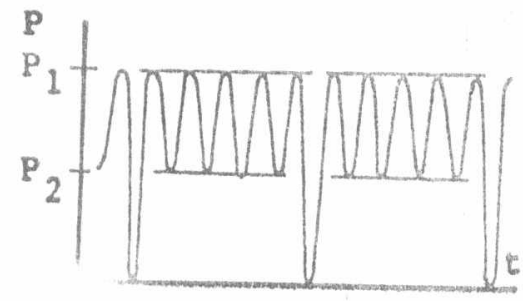

$c / n$

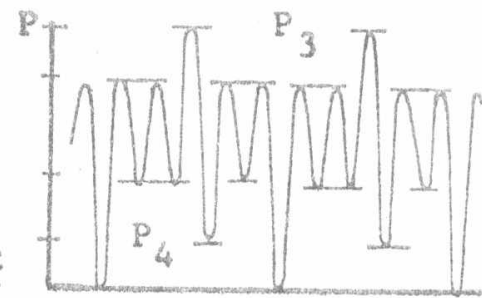

D

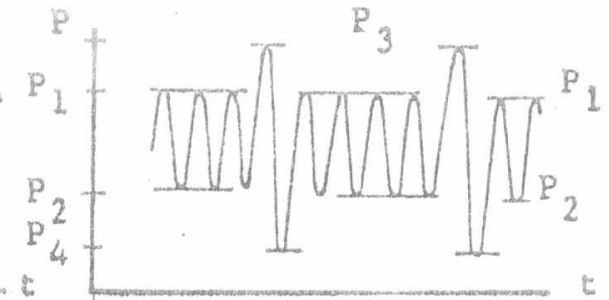

E

Pl (N)

$\mathrm{P} 2(\mathrm{~N})$

3940

11560

6970

(N)

P4 (N)

C.T.

6200

C.C.T. 18350

20486

3170

9424

Figure 1 : Patterns and Loading Values 
flight and would rspresnt the Ground-Air-Ground cycie(G.A.G.). Types $\mathrm{C} / \mathrm{n}$ ( $\mathrm{n}$ takes ralues $2,3,6,25$ and 69 ) however, represent the disturbed flight types in which B- cycles represent the flight disturbing lo:as (gust, manoeuvre, etc...). The same definition is valid for $S$ and $B-$ cycles in types $D$ and $E$.

\section{EXPERIMENTAI PRCSEDURE}

The materials used for this investigation are two aluminum alloys : $2124 \mathrm{~T} 351$ ( $\mathrm{AU} 4 \mathrm{G}$.) and $2618 \mathrm{AT} 851$ (AU $2 \mathrm{GN}$ ). The specimen geometries are: 1) compact tension specimens (C.T.) $1 / 2 \mathrm{~mm}$ thick, $75 \mathrm{~mm}$ wide/ ; 2) center crack tension specimen (C.C.T.) $/ 2 \mathrm{~mm}$ thick, $200 \mathrm{~mm}$ wide/. The chemical composition, mechanical properties and heat treatment are listed in tables 1,2 and 3 respectively. The test specimens were polished to a mirror finish in the vicinity of the crack path to facilim tate optical observation of the crack tip during crack growth measurements. Crack length was monitored. continuously by a travelling microscope with a resolusion of 0.01 mm. Tests were performed on servo-valve, electro-hydraulic INSTRON and MAYES testing machines of \pm 10 ton and \pm 5 ton $x$ espectively.

\begin{tabular}{|c|c|c|c|c|c|c|c|c|c|}
\hline ALLOY & Si & Fe & Cu & Mn & Mg & Cr & Ni & Zn & Ti \\
\hline 2124 T 351 & 0.09 & 0.21 & 1.40 & 0.63 & 1.50 & 0.01 & & 0.04 & 0.03 \\
261.8 AT 851. & 0.22 & 1.12 & 2.61 & 0.06 & 1.63 & 0.01 & 1.14 & 0.02 & 0.12 \\
\hline
\end{tabular}

TABLE 1 : Materials' chemical composition

\begin{tabular}{|c|c|c|c|c|}
\hline ALLOY & Sense & $\sigma_{0.2}$ MPa & $\sigma_{\text {mi MPa }}$ & A. \\
\hline 2124 T 351 & TL & 328 & 472 & 15.16 \\
2618 AT 851 & & 410 & 650 & 03 \\
\hline
\end{tabular}

TABIE 2 : Materials' tensile properties

\begin{tabular}{|l|l|}
\hline ALIOY & Heat treatment \\
\hline 2124 T 351 & $\begin{array}{l}\text { Solution heat treated, cold work-naturally aged } \\
\text { Solution heat treated, cold work-artificially } \\
\text { aged at } 1900 \mathrm{C}\end{array}$ \\
\hline
\end{tabular}

: TABLE 3 : Materials' heat treatment

All tests were run at a frequency of $10 \mathrm{~Hz}$ and in air at room : temperature. In order to measure the crack opening level ( op $_{\text {) }}$ :
a surface gauge located at the crack tip was used to plot the opening displacement ( $\delta$ ) against the load (P), tests and plots were made at a frequency of $0.2 \mathrm{HZ}$. The programmed block loading were generated by a mini-computer PDP 11 which pilots the testing machines continuously during the test. 


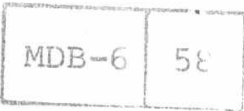

FIRST A.M.E. CONFERENCE

$\Gamma$

TEST RECILTS AND ANAIISTS

Constant Amplitude Loading

Fatique crack growth data in the form of a a/dN (mm/cycle)versus stress intensity factor range $\Delta K$ (MPr $\sqrt{m})$ for different cycle ratios $R$ and for the two thicknesses are represented in Fig. 2 The two aluminum allyos showed a significant effect of $\mathrm{R}$ ratio on their fatigue cracking. The effect of R ratio is ejther through the modification of the coefficient $C$ or the exponent in in the paris relation:

$$
\mathrm{da} / \mathrm{dN}=c(\Delta \mathrm{K})^{\mathrm{m}}
$$

Consequently, a higher propagation rates for higher $R$ ratios as pointed out in $/ 8,9,10 /$. For the same loading conditions. thick specimens (C.T.) showed higher propagation rates than thin ones (C.C.T.). This is due to the different states of stress which depend mainly on the through thickness constraints.
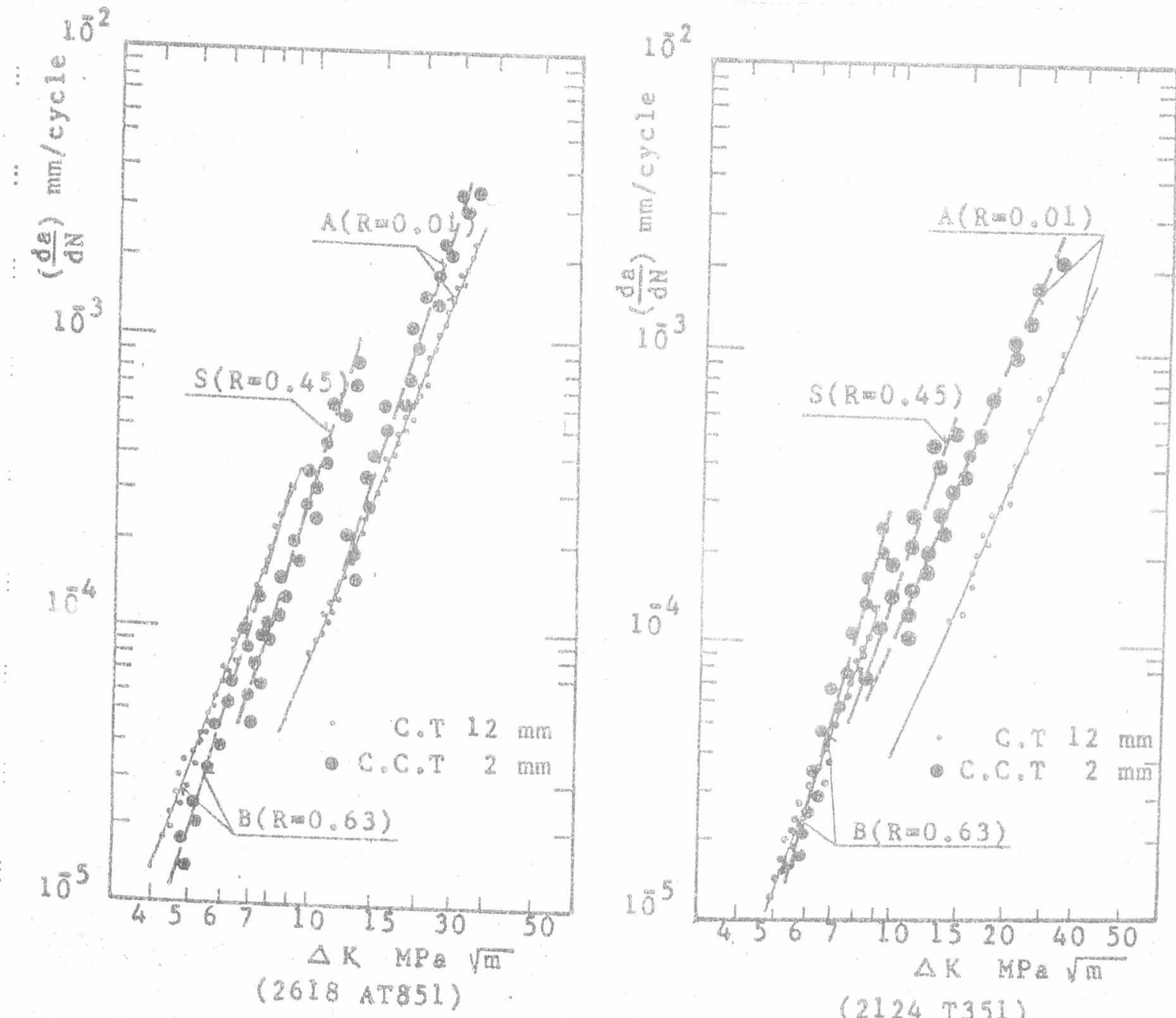

Figure 2: R-ratio and thickness effects on fatigue crack propagation.

i. 
Spectrum Isadings

Fatigue crack growth data obtained for C.T. specimens are shown in Fig. 3 in the form of a plots $a=f(N)$ where $N$ represents the number of flights (cycles for type $A$ or blocks for types $\mathrm{C} / \mathrm{n}$ ). Types $\mathrm{C} / \mathrm{n}$ are characterized by a constant maximum : load level $\left(P_{1}\right)$ and by one G.A.G. cycle which occurs once per ifight.

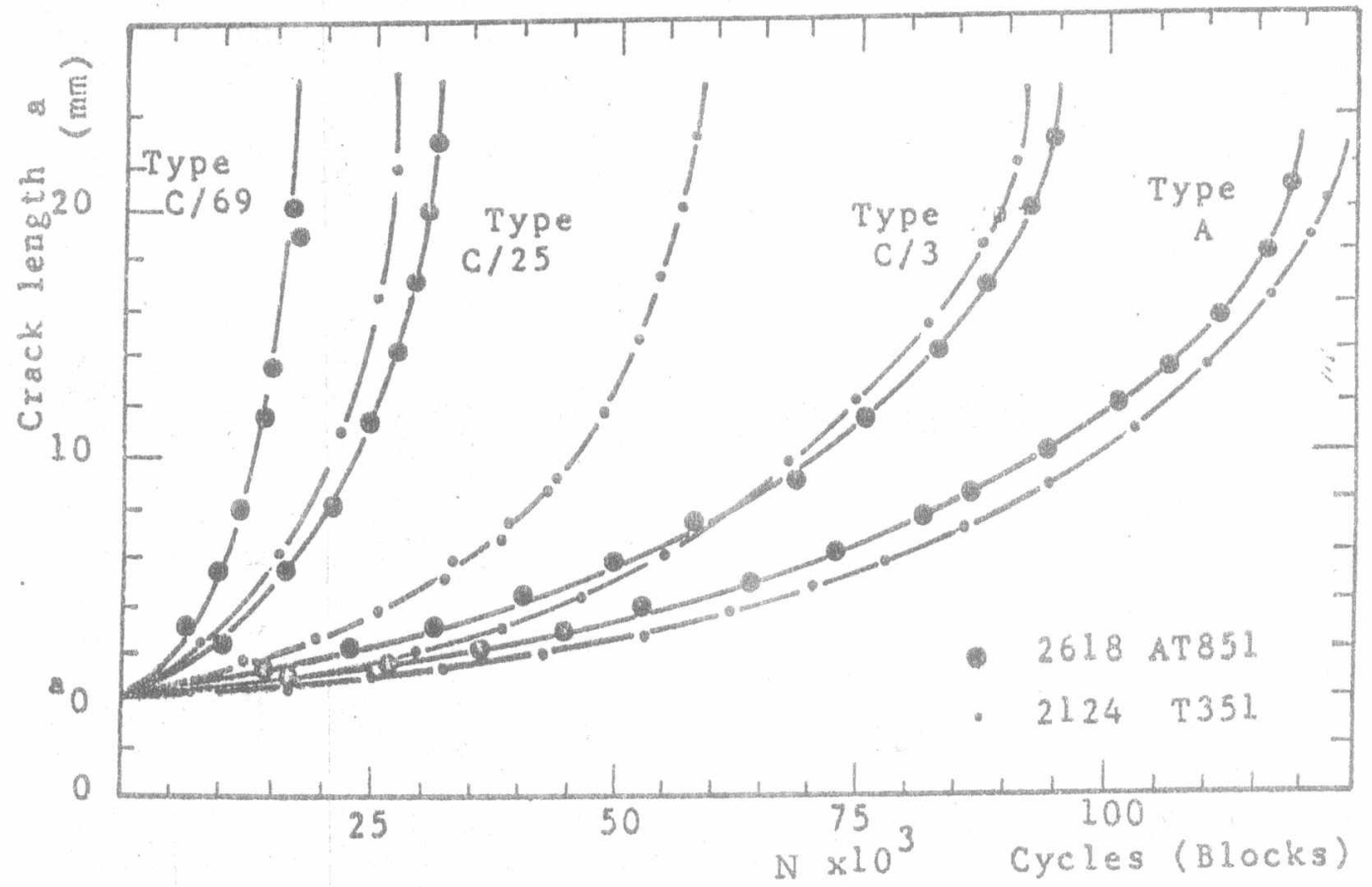

Figure 3 : Fatigue crack growth under different loading types.

Thus, distubed flights (types $\mathrm{C} / \mathrm{n}$ ) can be compared with simple non-disturbed flight (type A). Comparison being based

on number of flights to failure and crack growth rate per flight expressed as a function of $\mathrm{K}$ for different $\mathrm{C} / \mathrm{n}$ types as shown in Fig. 4. Consequenty, the influence of flight disturbances (B-cycles) on crack propagation is possibly investigated. The dashed lines in Fig. 4 represent the non -interaction summation of crack growth corresponding to

basic data of types $A$ and $B$. It is interesting to find $a$ good coincidence between these theoritically calculated growth rates and test data points for different types of $\mathrm{c} / \mathrm{n}$. This implies that it is only $\mathrm{R}$ ratio effects which caused these accelerations without any significant interaction effects. 

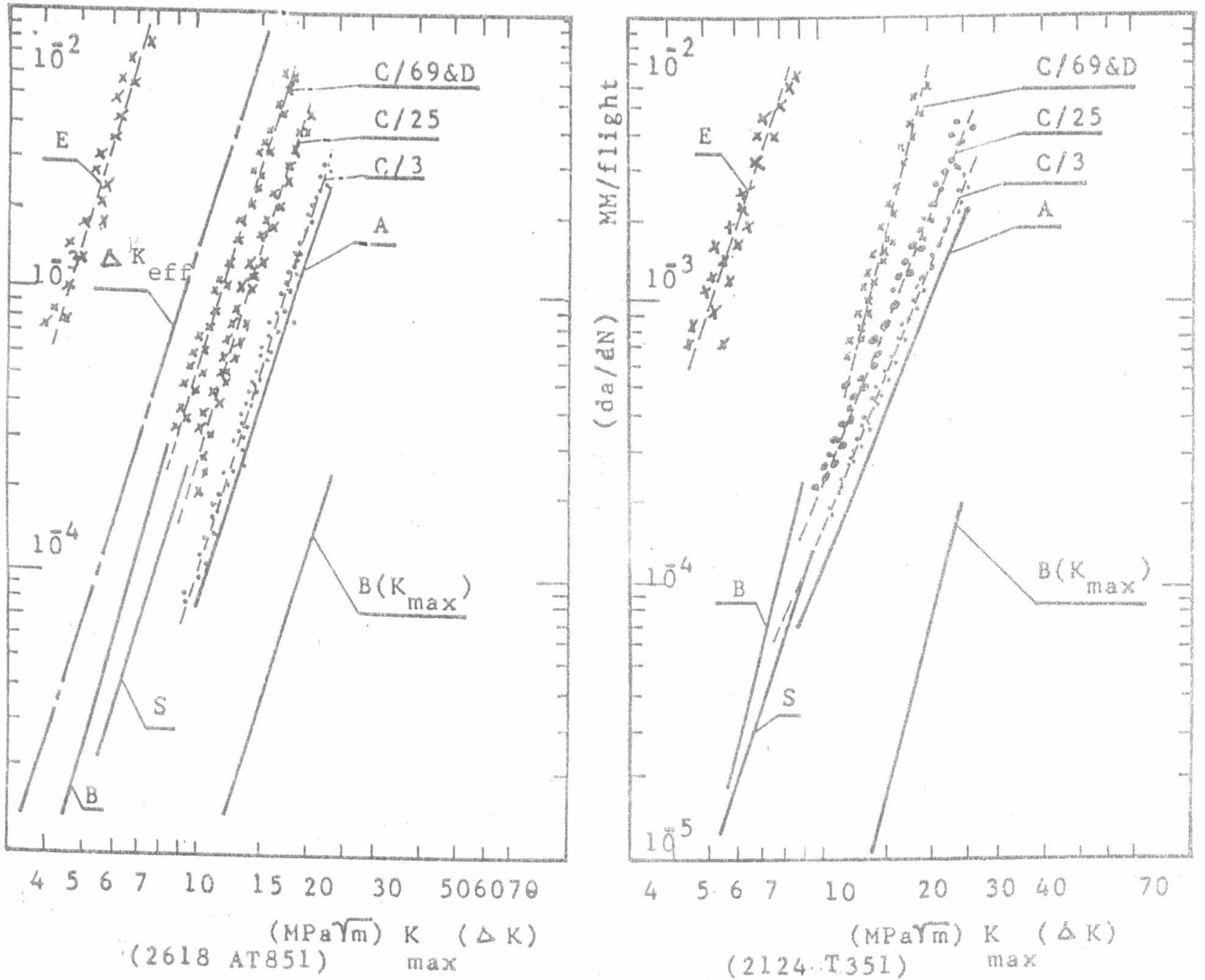

Figure 4 : Fatigue crack growth rate under different block loadings.

Analysis Based on Crack closure Concept

In an attempt to better understand the mechanism of crack propagation under spectrum loading, it was decided to measure the crack opening stress level on a $2 \mathrm{~mm}$ thick C.C.T. specimen of 212 T 351 under loading types $(A, C / 3$ and $C / 25)$. The same tech nique of Elber/11/ was used. Fig. 5 gives typical plots of $\mathrm{P}=\mathrm{f}(\delta)$ corresponding to each type of loading. It was difficult to measure $\mathrm{P}_{\mathrm{op}}$ during the low $\Delta \mathrm{K}$ cycles ( $\mathrm{B}$ - cycles) in the block, so we considered the modification of opening level $P_{0 p}$ on the G.A.G. cycle as representing the crack opening load $\left(P_{o p}\right)$ equiv. during the whole block. It is interesting to note : that the level of $\mathrm{P}_{\mathrm{op}}$ changes significantly with the number of $\mathrm{B}$-cycles in each block. The average values of $\alpha=\mathrm{P}_{\text {op }} / \mathrm{P}_{\max }$ are given in table 4

\begin{tabular}{|c|l|l|l|c|}
\hline TYPE & A & C/3 & C/25 & $B$ \\
\hline MEASURED $\propto$ & 0,5 & $0,61-0,63$ & 0,69 & 0,72 \\
\hline
\end{tabular}

L.. TABLE 4: Measured values of $\propto\left(P_{\text {op }} / \mathrm{P}_{\max }\right)$ 


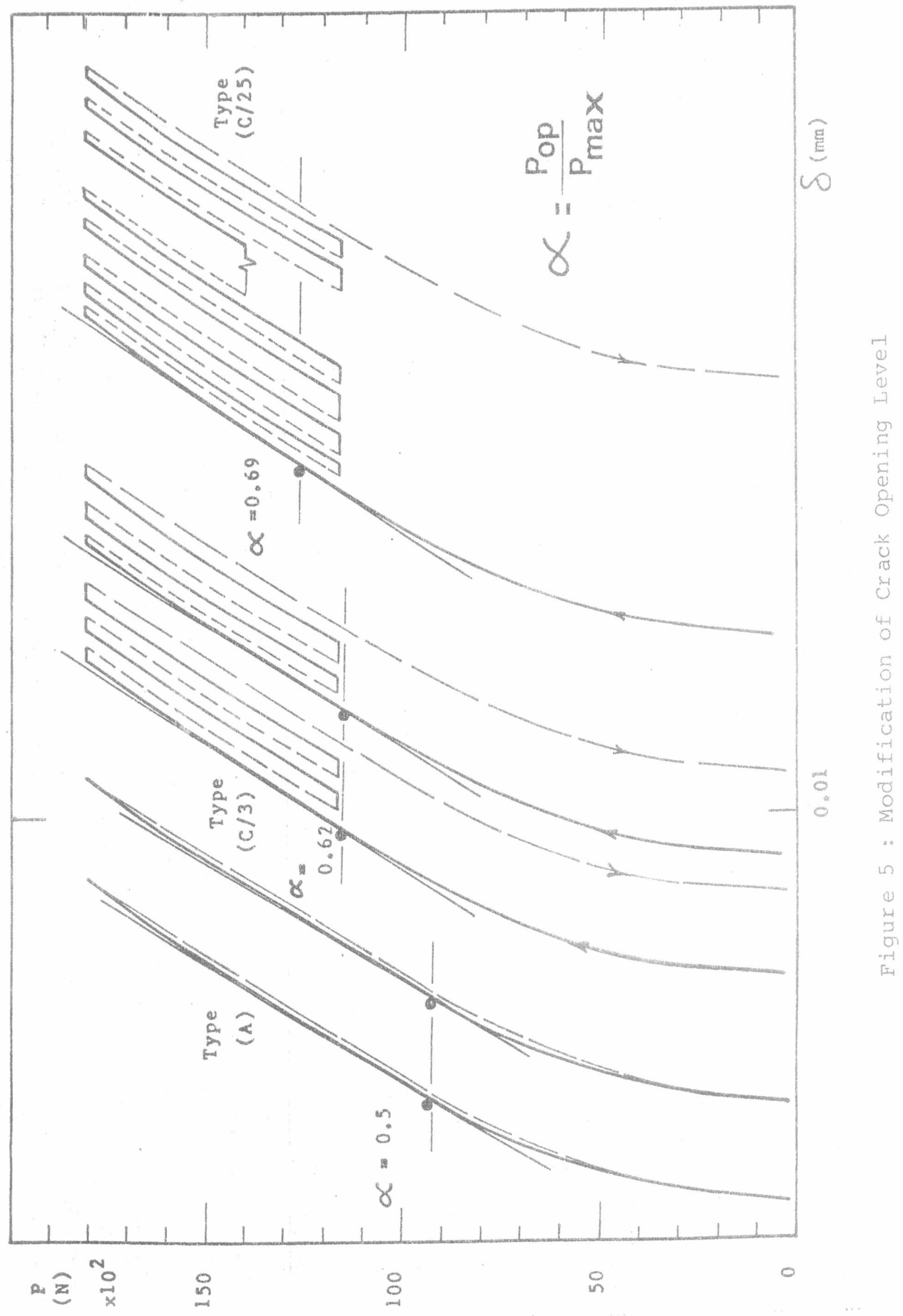




\begin{abstract}
$\begin{array}{llllllllllllllllllllllllllllllllllll} & \cdots & \cdots & \ldots & \ldots & \ldots & \ldots & \ldots & \ldots & \ldots & \ldots & \ldots & \ldots & \ldots & \ldots & \ldots & \ldots & \ldots & \ldots & \ldots & \ldots & \ldots & \ldots & \ldots & \ldots & \ldots & \ldots & \ldots & \ldots & \ldots & \ldots & \ldots & 7 \\ \vdots\end{array}$
: Based on Elber relation /11/

$\vdots \quad U=\frac{P_{\max }-P_{o p}}{P_{\max }-P_{\min }}=\frac{P_{\max }-P_{\text {op }}}{P_{\max }(1-R)}$

$\quad \alpha$ is defined as $\mathrm{P}_{\text {op }} / \mathrm{P}_{\max }$

$\vdots \quad U=\frac{1-\alpha}{1-R}$

: For aluminum alloys $U=0.5+0.4 \mathrm{R}$

This would yield that:

$\vdots=0.5+0.1 R+0.4 R^{2}$

As a first suggestion the ratio $\alpha$ for types $\mathrm{c} / \mathrm{n}$ will have 'values such that $\alpha_{A}<\alpha<\alpha_{B}$ depending on the number of B-cycles per block. Consequently, we can expect that the crack opening level under such sequence ( $P_{\text {max }}$ is kept constant) will be stabilized after some crack growth and remain relatively constant through the crack propagation under these regular, short and stationary spectrum loadings.
\end{abstract}

\title{
INTERPRETATION OF CRACKING MECHANISM
}

: Microfactography

The fracture surface is a finger print or a record of the loading experienced by the specimen. Study of the fracture surface through the use of the electron microscope provides cycle by cycle evidence, in the form of striation, of crack behaviour that normally can not be established from macroscopic observations /12/. Tested specimens corresponding to each type were examined through the scaning electron microw :scope type CAMBRIDGE - STEREOSCAN 100.

Different aspects of load - time history are easily recognized for different specra where striation groups representing in:dividual flight were identified as shown in Fig. 6 . Only the block types $\mathrm{C} / 2$ and $\mathrm{C} / 3$ showed some ambiguity in distinguishing the flight disturbing loads (B-cycles) from the G.A.G. :cycles. The fracture surfaces corresponding to load types C/6: C/25 and $\mathrm{C} / 69$ showed a clear correspondance between the spectrum and the striations. We think trat in these blocks. the un:loading part nf the(Air-ground) cycle (A) presents a heavy cyclic deformation that changes microscopically the cracking plane and cycles B reorient it. The first few cycles of B:Cycles are enough to regain the cracking plane and their striations are well marked on this disorientation. This is clearly present in Fig. 6. Thus, a well defined closure of the :crack does exist in each and every cycle forming these types : of spectrum. This would emphasize that crack closure is an iessential factor in defining the striation during fatigue 


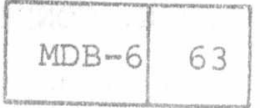

6

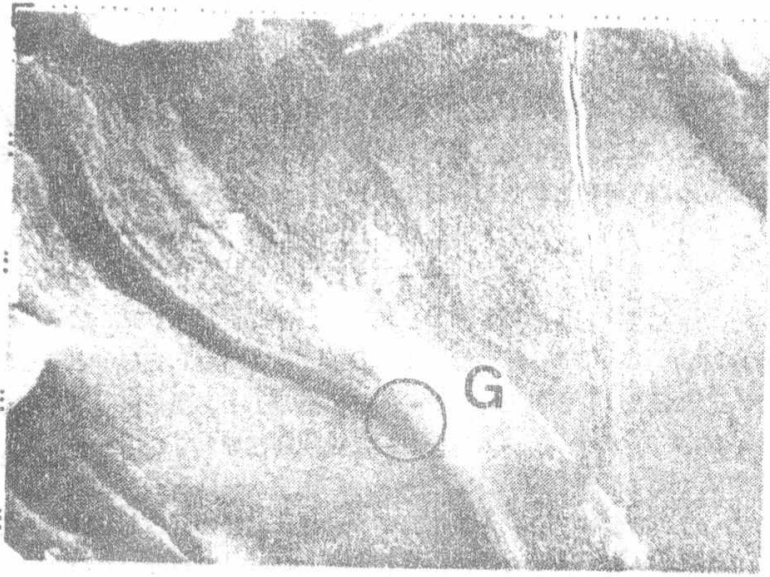

Type $0 / 69 \times 1.500$

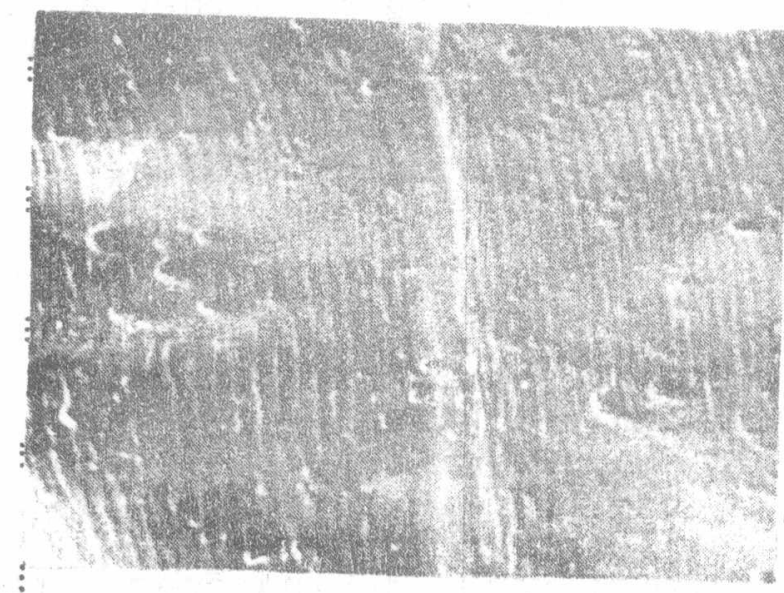

Type $c / 25 \times 5000$

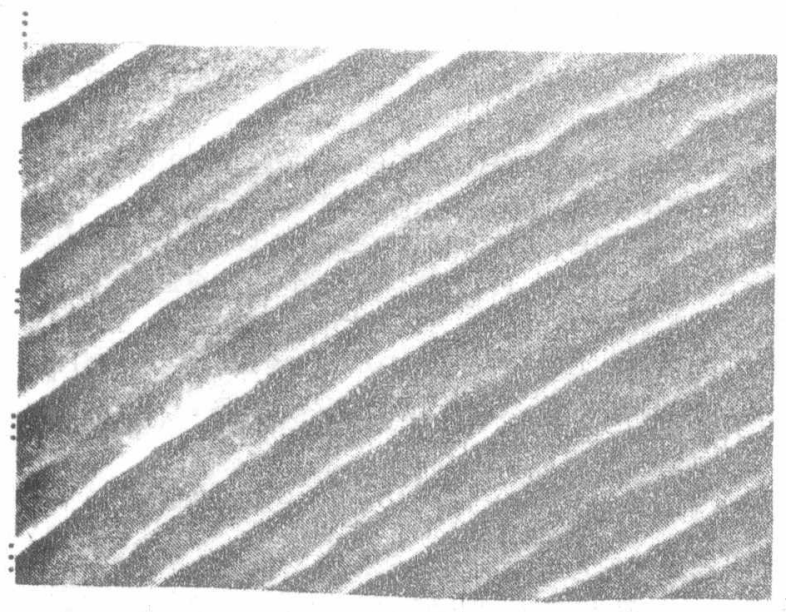

: Type $c / 3 \times 20.000$

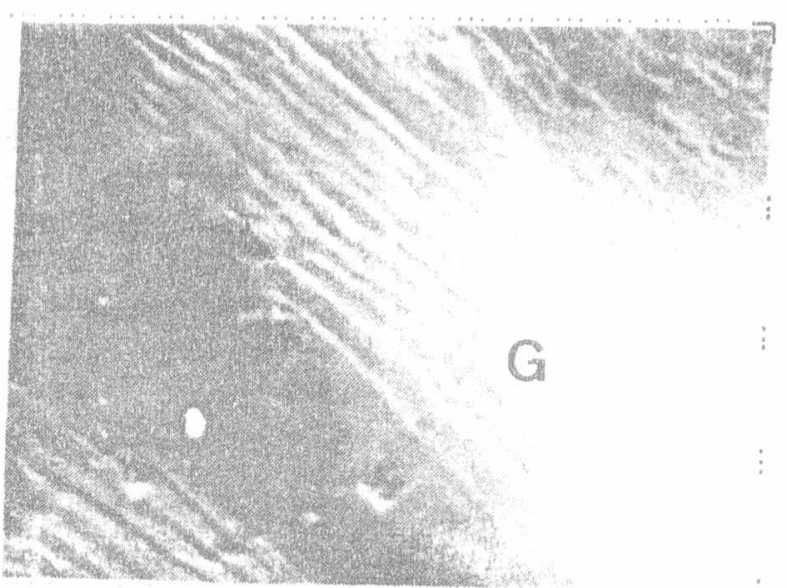

Type C/69 × 70.000

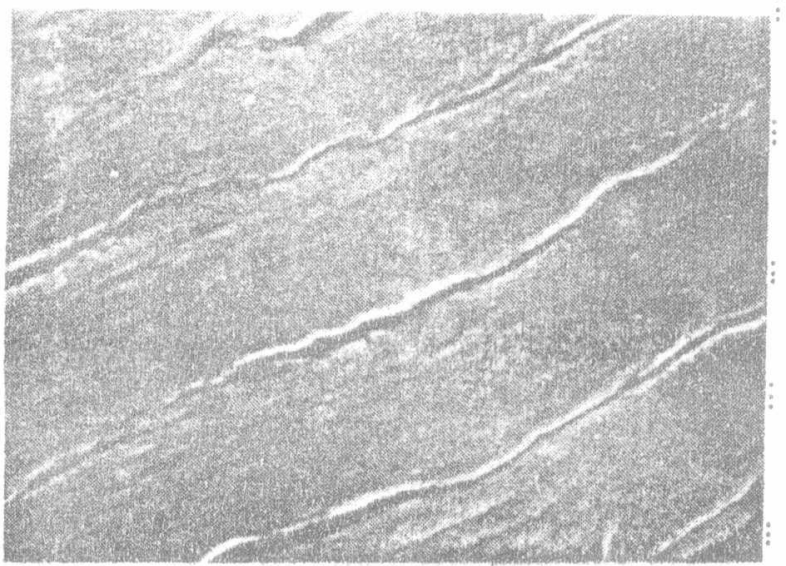

Type $0 / 6 \times 20.000$

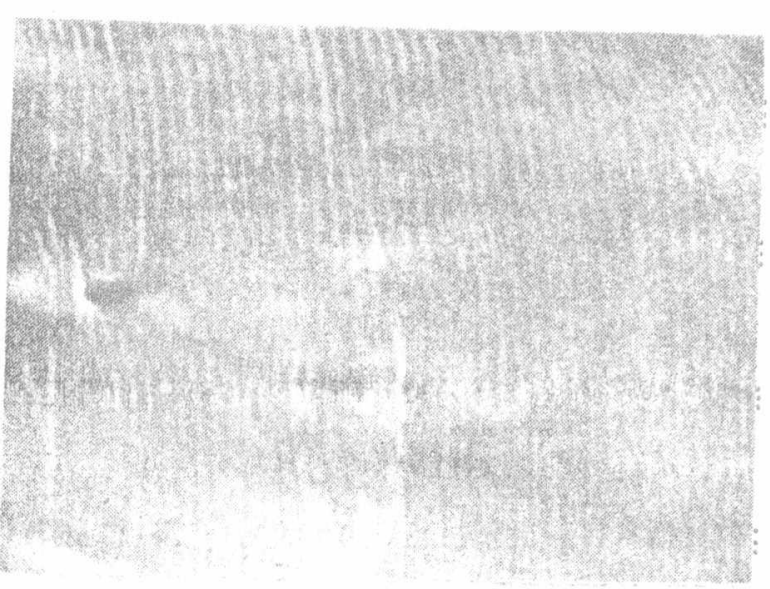

Type C/2 x 4000

Material : Aluminum alloy $2124 \mathrm{~T} 351$

Figure 6: Microfractography and interpretation of Fatigue Cracking Mechanism.

L.. 
crack propagation. Fracture surface corresponding to type $\mathrm{C} / 3$ showed equal striations without distinguishing between cycles $B$ and $A$. Considering the striation mechanism proposed hereabove, the provoked ambiguity can be attributed to the fact that in type $\mathrm{C} / 3$, two cycles of $\mathrm{B}$ are not sufficient to reorient the cracking plane being disoriented by every unload- : ing $A$. This leads to a continuous microscopically curregated fracture surface. Besides, the fact that the stabilized crack opening level ( $P \circ p$ ) equiv for type $C / 3$ is very close to $\left(P_{\min }\right)$ : of loading level $B$ in the block. This would imply that an instantaneous crack closure and crack opening is produced at $\left(P_{\text {min }}\right)_{B}$. Consequently, equal striations corresponding to: levels $A$ and $B$ are to be expected as found in Fig.6.

Whereas, in type $\mathrm{C} / 2$ the crack opening level ( $\mathrm{P}$ op)equiv is far low from $\left(\mathrm{P}_{\mathrm{min}}\right)_{B}$ in the block. This would suggest either a : : very poor or even no crack closure during the one B-cycle in the block type $\mathrm{C} / 2$. Consequently, the microfractography of this type would only show striations corresponding to the :G.A.G. cycle in each block during which the crack closure does exist.

$\vdots$ CONCLUSIONS

1) Aluminum alloys respond significantly to variation of the : cycle ratio $R\left(P_{\min } / P_{\max }\right)$. For a given value of $\Delta K$ the crack growth rate increases pronoucely with $R$. The ratio $R$ has a simultaneous effect on the translation of Paris relation.

2) Linear damage accumulation is established during crack propagation under the studied spectra where $\mathrm{R}$ ratio effects play the essential role.

3) The crack closure gives a significant contribution to the investigation of fatigue crack propagation under variable amplitude loadings.

4) Microfractography and its interpretation are essential tools in understanding fatigue crack propagation.

5) Crack closure is necessary to define the striations. The significant markings (deep valleys or high peaks) are associated with the G.A.G. cycle and the peak flight load cycle. They appear to be caused by the heavy deformations

: due to the large unloadings preceding the B-cycles.

\section{REFERENCES}

/1/ De Koning, A.U.,"A Simple Crack Closure Model for Prediction of Fatigue Crack Growth Rates Under Variable Amplitude Loading", ASTM.STP 743, 63-85, (1981).

/2/ Schijve, J. " "Observations on the Prediction of Fatigue Crack Growth Propagation Under Variable Amplitude Loading", ASTM. STP 595, 3-23, (1976).

/3/ Schijve,J." "The Accumulation of Fatigue Damage in Aircraft Materials and Structure", AGARD ograph No. 157, (1972).

/4/ Schijve,j.,"Four Lectures on Fatigue Crack Growth, Engin- : eering Fracture Mech。,vol.11,167-221, (1979). 


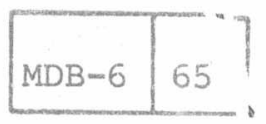

!

/ 5/ Elber,W.,"E-1ivalent Constant Amplitude Concept for crack Growth Under Spectrum Loading, ASTM。STP 595, 236-250, (1976).

/ 6/ De Jonge,J.B. et aI," A Standardized Load Sequence for Flight Simula: on Fests on Transport A/C Wing Structures", IBF Bericht. FE 106 NLR TR $73029 \mathrm{~N}_{8}$ (March 1973)。

/ 7/ Gabra,M.S. "P. Igrammed Block Loading Fatiglie Crack

: Growth in Alum. um Alloys" International Symposium on Fracture Mech. W B Beijing, China, (Nov, 1983)。

/ 8/ Broek,D. and Sch"jve,J." "The Influence of the Mean

: Stress on the Fai. gue Cracks in Light Alloys Sheet", Aircraft Engineering, 10, (1967)。

/ 9/ Gunn,N.J., "Fatigun Cracking Rates and Residual Strength of Eight Al. Alloys, R.A.E. Tech. Rept 64024, (October 1964).

: /10/ Pearson,S., "The Eff:ct of Mean Stress on Fatigue Crack Propagation in Half ach Thick Specimens of Al-Alloys, R.A.E. Tech. Rept. 68:97, (1968).

: /ll/ Elber,W., "The Signif'cance of Fatigue Crack Closure", ASTM.STP $486,230-242$, (1971)。

/12/ Abelkis,P.R.,"Use of Mjcrofractography in the Study of Fatigue Crack Propagation Under Spectrum Loading", ASTM. STP $645,213-234,(1978)$. 
